\title{
Cibercultura e literatura: hipertexto e as novas arquiteturas textuais
}

\author{
Luiz Antonio Garcia Diniz
}

\begin{abstract}
Ou somos, todos os Eu que estive aqui
[ou estiveram,

Uma série de contas-entes ligadas por

[um fio-memória,

Uma série de sonhos de mim, de alguém

[de fora de mim?

Álvaro de Campos*
\end{abstract}

Falar sobre hipertex to, cibercultura e literatura na era da tecnologia digital equivale a abordar questões ainda novas, andar por caminhos pouco explorados e, diante desse quadro, arriscar-se a relacionar essas questões com as teorias literárias. Nossa proposta é, inicialmente, definir o que representam para nós esses termos e, a seguir, relacioná-los com o que entendemos ser a construção de uma nova textualidade criada pela mídia eletrônica. Nesse sentido, buscaremos apontar e revelar um distanciamento ou uma complementaridade entre a literatura do "papel impresso" e a "literatura digital", refletindo igualmente sobre as relações socioculturais decorrentes desse fazer técnico.

Como o hipertexto e a cibercultura se inscrevem em um espaço digital (ciberespaço), nossa hipótese é que tal espaço se tornou uma construção análoga ao que entendemos por uma cidade moderna, artefato ou construção textual, que nomearemos como cibercidade, na qual essa nova linguagem se "instala". Esta se constitui em uma das formas contemporâneas do texto literário, e é com esse material que nossa reflexão se envolve. Para Lemos, a cibercultura é a "forma sociocultural que emerge da relação simbiótica entre a sociedade, a cultura e as novas tecnologias de base micro-eletrônica que surgiram com a convergência das telecomunicações com a informática na década de 1970 "*. Ora, para haver cibercultura e os desdobramentos teóricos que esse conceito impõe, é necessária a

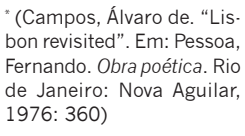
bon revisited". Em: Pessoa, Fernando. Obra poética. Rio de Janeiro: Nova Aguilar, 1976: 360) "(Lemos, André. "Ciber-
cultura: alguns pontos
para compreender nossa
época". Em: Lemos, André
\& Cunha, Paulo (org.).
Olhares sobre a cibercultu-
ra. Porto Alegre: Sulina,
2003: 12) 
"(Rosa, Jorge Martins. "Cibercultura em construção", Revista de Comunicação e Linguagens. Lisboa: Relógio D’Água, 2001: 319.33)

"(Ihde, Don. Technics and práxis: a philosophy of tehc. nology. Dorrecht/Boston: D. Reidel, 1979) existência de sociedades produtoras desses objetos culturais ou bens simbólicos, bem como grupos sociais produtores e consumidores desses mesmos bens, situados, aqui, com as expressões socioculturais das chamadas comunidades virtuais.

Não se trata de problematizar a existência sociológica das comunidades virtuais, do ponto de vista das questões relacionadas às identidades, considerando os processos estatísticos que pretendem agrupar indivíduos, ao traçar um perfil por meio da seleção (arbitrária) de certas características que lhes confeririam um "tipo", como sexualidade, áreas de interesse etc., ou seja, um conjunto de traços identitários configuradores de uma tipologia capaz de agrupar tipos ou de aproximá-los por meio de uma busca nas comunidades. Partiremos, então, como recorte reflexivo, do pressuposto da existência concreta das comunidades virtuais e de suas atuações, afirmando por meio de suas práticas a realidade "material" do que seria uma comunidade "imaterial". Evidentemente, a passagem de uma para outra revela, por ora, uma certa divisão de territórios ainda perceptíveis. Daí as expressões off line e on line serem, talvez, necessárias para conceituar "lugares" que parecem ainda distintos e dotados de atribuições específicas.

Jorge Martins Rosa*, ao recorrer à conceituação de Don Ihde* para definir os conceitos de on line e off line, refletiu sobre um conjunto de dados referentes a esses conceitos que poderia ser esquematizado do seguinte modo: estamos off line quando recorremos à tecnologia unicamente como estrutura informacional, disponibilizada na rede e com a qual interagimos, como redes de prestação de serviços, bancos, canais de consultas para pesquisas acadêmicas, dicionários etc.; por sua vez, seria caracterizada uma situação de sujeito on line no caso de haver a consciência de um duplo espaço físico em que podemos entrar e sair, e, radicalizando de maneira hipotética, eventualmente não sair, como se pode observar em filmes como Matrix (Andy Wachowski e Larry Wachowski, 1999) e Sid 6.7 (Brett Leonard, 1995). Assim, a título de exemplo, observamos que há uma diferença qualitativa que incide na construção desse sujeito on line e off line, entre indivíduos que pesquisam na rede com objetivos específicos e aqueles que permanecem horas navegando e interagindo em salas de bate-papo. Aventaríamos, ainda, a possibilidade não remota de esses dois mundos se dissolverem na materialidade própria a cada um deles, como nos dois filmes acima citados. 
Apenas como forma de introdução desses conceitos, poderíamos acrescentar que o fato de não haver diferença alguma entre essas duas realidades, algo que particulariza a forma com que lidamos com a tecnologia, tem a ver com a relação que estabelecemos com ela. Posto isso, a relação "amplificadora" postulada por Ihde como constituinte da categoria on line é a que privilegiaremos nesse estudo, ou seja, aquela que pretende pensar a cibercultura como constructo - algo redundante, uma vez que toda cultura é um processo - gerador de textos e composto de indivíduos "amplificados" ou on line. São esses, em primeira instância, alguns dos atributos relacionados às novas textualidades no século XXI.

Passamos, assim, de uma relação hermenêutica, tomando a tecnologia como algo que faz parte do mundo (off line ou nãoplugada), a uma relação amplificada: a tecnologia fazendo parte de nós. Há, nesse campo reflexivo, muitos aspectos que não cabem no âmbito deste estudo. Acreditamos, porém, que a conceituação de sujeitos "não plugados", relacionados com as tecnologias interpretativas, e "plugados", relacionados com as tecnologias amplificadoras, revela novas formas de reflexão sobre os sujeitos contemporâneos tomados em suas relações com as tecnologias. Tal situação indica igualmente o surgimento de novos sujeitos originários ou produtos da cibernética, como o ciborg.. Desse modo, a dualidade clássica entre homem/ máquina, manifestada na ficção científica e na produção cinematográfica dos anos pós-1940, exacerba-se na cultura contemporânea.

O que essa literatura deixa transparecer é uma passagem entre os primeiros ciborgs, - seres compostos de elementos biológicos e maquínicos - e aqueles atualmente representados em filmes como O exterminador do futuro II, de James Cameron (1991), que retrata a história de um ciborg cujo organismo é composto de metal líquido e completamente desvencilhado dos maquinismos herdados do século XX. A desvantagem do ciborg composto de peças mecânicas ou de elementos eletrônicos complementares, que buscam potenciar as qualidades do homem biológico para aperfeiçoá-lo (T-800) em relação ao de metal líquido (T-1000) é bastante clara. Esse ciborg corresponderia ao que Lúcia Santaella* classifica como um produto da segunda onda da cibernética, e o antigo, à primeira. A ampliação da ressonância polissêmica do ciborg como metáfora do corpo

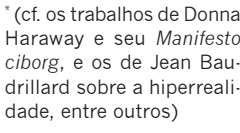

"(cf. os trabalhos de Donna Haraway e seu Manifesto ciborg, e os de Jean Bau drillard sobre a hiperreal dade, entre outros) 
"(Joyce, Michael, Afternoon, a story, 1985. Disponíve em http://www.eastgate. com/hypertext/Authors. html; Moulthrop, Stuart. Victoria garden. Disponive em http//www.eastgate. com/catalog/victoryGar den.html, e Hegirascope. Disponível em http://www. eastgate.com/hypertext/ Authors.html; Pais, Ma nuel. Metacarne. Lisboa: Oficina do Livro, 2000. Brandenbourger, Anne.Cé. cile. Apparitions inquietan tes. Editions 00h00.com 02/2000) humano em vias de desaparecimento ou como artefato obsoleto é tema recorrente tanto em trabalhos teóricos como o de Santaella quanto em produções artísticas contemporâneas.

Seja no campo artístico, seja no campo prático dos serviços, a cibercultura é o presente, e não o futuro, uma vez que serviços antes oferecidos pela cidade moderna participam da cibercidade e estão disponibilizados na rede, entre os quais homebankings, cartões inteligentes, celulares, palms, pages, voto eletrônico, imposto de renda e jogos eletrônicos. Por que não o seria para a literatura contemporânea recheada de referências digitais? Ver, a esse respeito, obras que nomeamos como hiperficção: Afternoon, a story, do americano Michael Joyce; Victory garden, de Stuart Moulthrop, ou ainda sua obra referencial Hegirascope; e Metacarne, de Manuel Pais. Na França, entre outros autores, Anne-Cécile Brandenbourger e sua obra hiperficional Apparitions inquiétantes*.

Afastando-nos um pouco da hiperficção, há exemplos hipertextuais relacionados a redes comunicacionais como o Orkut, cuja designação provém do nome de seu criador e constitui uma comunidade virtual que reúne milhões de usuários, ou seja, é um exemplo fora das hiperficções, porém situado nas fronteiras de uma reflexão entre o literário e o não-literário. Ele se revela, em sua construção, uma modalidade própria ao hipertexto e contribui não só, segundo uma análise de sua estrutura, para apreender o modus operandi hipertextual, como também para nos situarmos como receptores/produtores no campo da criação textual.

A organização arquitetônica do Orkuté construída de uma forma que provoca, desde nossa entrada na rede, a multiplicação exponencial da base inicial de dados. Por exemplo, no primeiro contato estabelecido com sua interface na abertura da página, lemos: "You are connected to 3.397.230 people through 4 friends" (cf. Figura 1, na página 214) ou "Você está conectado a 3.397.230 usuários por um ou mais amigos”. Basta, portanto, apenas uma unidade informacional, um elo, um "amigo", para que a informação em rede se dissemine pelo complexo relacional estruturado por milhões de centros identitários que se desdobram em nuanças cada vez mais singularizadas na construção hipertextual. Há uma multiplicação de tipo viral, criada por uma geometria de crescimento exponencial que proporciona uma relação de sinédoque perfeita: a célula 
inicial é o todo e o todo é um fragmento isolado, uma unidade construtiva da textualidade em construção.

Há, no Orkut, aspectos sinérgicos que nos remetem à convivência do arcaico com as altas tecnologias digitais construtoras dessas redes comunicacionais, traços próprios da pós-modernidade. Uma sinergia entre o "eu” contemporâneo (pós-moderno) e o "nós" saudosista (moderno) consistindo em uma espécie de tropismo, quando, por exemplo, as unidades informacionais (amigos) reagem analogicamente aos estímulos produzidos no contato com os outros amigos. Em decorrência dessa estrutura discursiva, proliferam sentimentos como desejo, vontade de conhecimento e procura de outros imaginários, que implicam a totalidade do universo cultural supostamente representado por suas interfaces, por meio de figuras (grupos comunitários) que reúnem fragmentos do que o "amigo" (unidade informacional) espera corresponder à sua unidade subjetiva. $\mathrm{O}$ que, a nosso ver, não é passível de definição, posto que a sua "unidade" só poderia ser singularizada em contraposição às outras unidades, em relação a elas, cada uma delas representando alguma particularidade que a diferencie.

Instaurar um percurso nessa trama hipertextual é participar de cada singularização que nos é proposta mediante estímulos culturais/sensoriais, fazendo-nos avançar (ou recuar) cada vez mais na complexa rede. Não é possível restabelecer ou mapear cada incursão nos meandros dos processos de subjetivação, pois estes são únicos e estão sujeitos a variáveis ilimitadas, relativas ao instante do estabelecimento comunicacional, ao estado emocional, psíquico ou libidinal. Contrariamente a uma leitura tradicional linear, esse complexo relacional estruturado em rede permite ir "além" do imaginário intelectual, para se dirigir ao encontro de possíveis realizações inscritas no plano do "real", ainda que sob a forma de uma projeção utópica em direção ao "nós" e, para tanto, abandonando o distópico "eu”. Para uma melhor visualização dessa espacialidade, sugerimos o quadro abaixo:

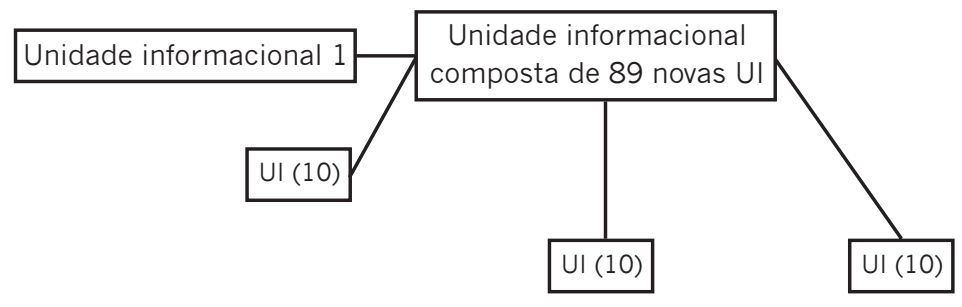


A título de exemplo, uma unidade informacional possuindo 89 "amigos" = 89 unidades informacionais (U.I.), em que cada uma nos abre um rizoma informacional de dez U.I., e cada uma dessas dez traz dez referências, terá uma multiplicação inicial que vai de 89 a 8.900 . A sequiência subjacente a essa estrutura geométrica é exponencial e infinita.

Além dos "amigos", denominados por nós unidades informacionais, há outros dados que fazem parte da estrutura hipertextual, como as comunidades compostas, por sua vez, por milhares de U.I. que remetem a uma unidade informacional rizomática (espécie de célula inicial); essa formação, metaforicamente "arborescente", é a condição da própria existência do hipertexto como complexo comunicacional. Tais dados pertencem ao paratexto, ou seja, a uma estrutura funcional que permite a navegação hipertextual. No paratexto do Orkut, há ainda outras unidades informacionais como o "álbum" de fotos, o scrapbook, a descrição do personagem por ele próprio e comentários agregados aos "testimonials", como se pode observar na figura representada pela interface abaixo:

\section{Figura 1}

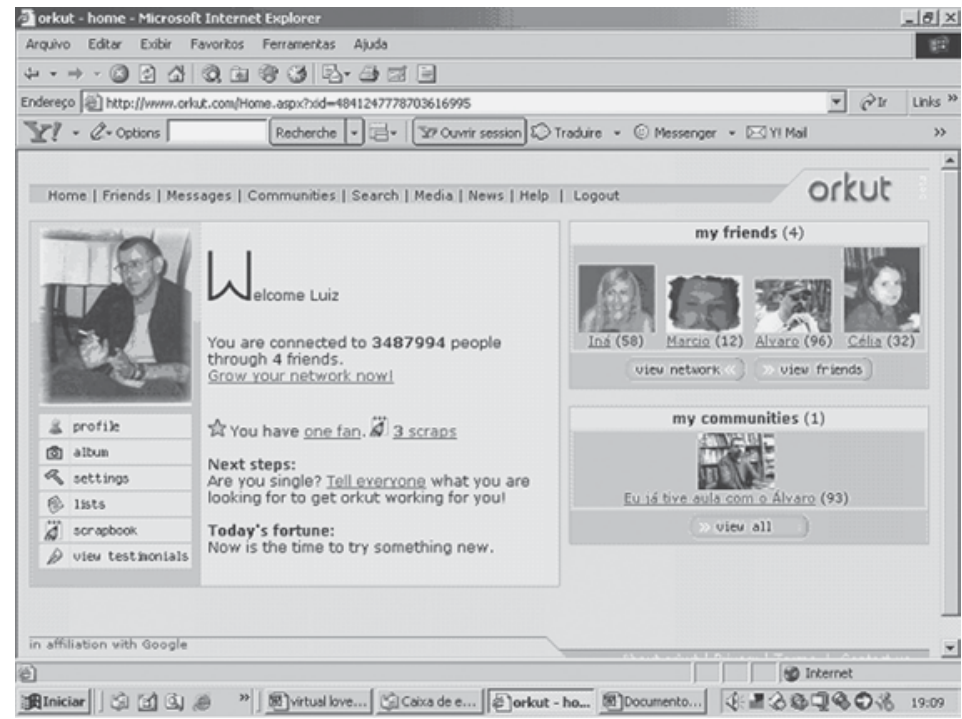

A nosso ver, a questão para os estudos literários é esta: como abordar essa nova linguagem do ponto de vista da teoria 
da literatura, se toda técnica altera e transforma nossa percepção e, conseqüentemente, nossa apreensão de um universo cultural? Acreditamos que as novas ferramentas avançadas por esse fazer digital nos ajudarão na construção de um fazer teórico, mas, é preciso reconhecer, ainda estamos esboçando formas reflexivas capazes de abordar esse novo imaginário.

Para Pierre Lévy, o hipertexto, composto ou não de sons e imagens, é algo que, por se estruturar em rede, opõe-se ao texto linear: "assim, o hipertex to seria constituído de nós (os elementos de informação, parágrafos, páginas, imagens, seqüências musicais etc.) e de ligação entre esses nós (referências, notas, indicadores, botões que efetuam a passagem de um nó para outro)"**. Esse autor estima que a leitura de uma enciclopédia clássica já configura uma estrutura hipertextual, se consideradas suas ferramentas de apoio: dicionários, léxicos e sumários. Patrícia San Payo, em seu ensaio "A máquina-literatura”, ressalta que, para Landow, autores como Barthes, Foucault e Derrida evocaram em seus textos conceitos diretamente relacionados à estrutura do hipertexto: as lexias em Barthes, os conceitos de epistema e função do autor em Foucault, e a natureza teórica dos escritos e a paginação de Glas e La vérité en peinture, de Derrida, evocam as de um texto multimídia*.

Hoje, uma das perspectivas para os estudos literários, se pensarmos em construir ferramentas de análise teórica, seria uma construção reflexiva com foco nas novas produções literárias, produtos da cibercultura. Desse modo, conviria iniciar uma reflexão crítica flexível que dê conta, mediante um instrumental analítico, de ao menos parte do conjunto de expressões textuais que a Internet propõe. É claro que isso será o início de um trabalho bastante árduo, porém necessário: um trabalho que contemple analiticamente as novas interfaces do hipertexto, entre as quais o cruzamento de linguagens diferentes e o surgimento de novos signos prosódicos e da escritura ideogramática, como material de análise apropriado às formas construtivas do texto no início do século XXI e às produções literárias que lhes correspondem.

As novas configurações que as nets propõem, no âmbito das relações na www, implicam novas interfaces comunicacionais que determinam novas relações de temporalidade. Como mostra Pierre Levy, "nas sociedades orais, as mensagens discursivas são sempre recebidas no mesmo contex to em que são produzidas"*. Com o aparecimento da escrita, essas relações mudaram

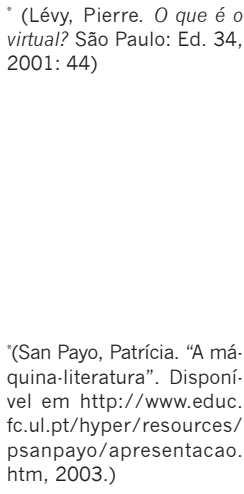

"(San Payo, Patrícia. "A má quina-literatura". Disponí. vel em http://www.educ fc.ul.pt/hyper/resources/ psanpayo/apresentacao. htm, 2003.)

" (Lévy, Pierre. Cibercultura. 15) 
e o tex to se deslocou de seu contexto, do lugar e época em que foi escrito, tornando possível ler um texto escrito há cinco mil anos e a dez mil quilômetros de distância. Para que esse empecilho fosse corrigido, as mensagens passaram a ter, então, caráter universal, a fim de que mantivessem sua "verdade" e pudessem ser lidas em qualquer lugar e época: as religiões, as ciências, os direitos do homem etc. Graças a essa "estaticidade", foi possível à escrita adquirir uma universalidade construída às custas da redução e da fixação de sentidos: um universal totalizante. É oportuno lembrar aqui a hipótese levantada por Pierre Levy: na cibercultura, a co-presença das mensagens retorna a um contex to de semelhança característico das sociedades orais, tratando-se de um fato relacionado com a simultaneidade entre a emissão e a recepção dos enunciados. Há, porém, diferenças na cibercultura e em outra escala. Para Lévy, a nova universalidade não depende mais da auto-suficiência textual, da autoancoragem da sua significação. A "universalidade" é elaborada pela interconexão e inter-relação das mensagens entre si, por meio de elos permanentemente criados com as comunidades virtuais. São elas que, sob uma dinâmica própria, conferida a um objeto em construção, atribuirão sentidos aos enunciados caracterizados por uma constante renovação e, conseqüentemente, em uma situação de eterna evanescência e fluidez, que são atributos inscritos no campo das significações.

Essa volta à temporalidade das sociedades orais quer dizer, entre outras coisas, uma ruptura com o pensamento totalizante e universalista que caracteriza a sociedade moderna, conferindo a essa nova sociedade características pós-modernas ou marcadas por manifestações culturais contemporâneas produzidas pelas sociedades pós-industriais. O que está em jogo, na temporalidade da era digital, é a defasagem existente entre a presentificação instaurada pela relação em rede e a inexistência da história como fluxo linear, revelada pela fatalidade da degradação exterior. O corpo nos trai, evidenciando sua obsolescência, e daí a criação das realidades virtuais como anulação absoluta do biológico.

Nessa construção permanente, a textualidade, fruto da interação de milhares de autores (vozes), inviabiliza a busca moderna de estabelecimento de valores e verdades universais. O que há, a rigor, são micro-totalidades em permanente construção. Assim, no interior das comunidades virtuais, constrói-se 
cotidianamente um texto com a participação de inúmeras pessoas, que contribuem para a realização de uma estrutura textual jamais imaginada, levando-nos a reconhecer como uma das características desse texto uma certa fragmentação e o deslocamento de seu centro, sobretudo no que se refere a questões como autoria e identidade.

Não podemos confundir, entretanto, fragmentação e fractalidade. A fractalidade caracteriza essa nova linguagem, constituindo-se em um conjunto de nós, de referências que nos "expulsam" de um centro estático e nos remetem continuamente - em um movimento de vai-e-vem - a milhares de novos campos de interesse. A fractalidade é, a nosso ver, a nova forma de temporalidade inscrita na estrutura textual da era digital, responsável pelo intercâmbio de milhares de informações que circulam na rede, de maneira inteiramente distinta da linearidade do texto tradicional.

Essa reflexão, portanto, é o eixo fundamental para abordar o hipertexto, visto aqui como fenômeno contemporâneo e análogo àquele causado pela invenção do livro impresso. As novas questões que a cultura do livro impresso provocou, como as noções de autoria, temporalidade e universalidade da cultura, traduzidas nas noções de ciência e religião, entre outras, opõem-se à tradição oral, em que a produção cultural era sempre comunitária. Em conseqüência, por intermédio de um processo histórico, encontrará seu "pendant" na digitalidade e na cibercultura.

Nízia Villaça, ao citar Michel Serres, considera que há evidências na relação entre o novo e o que o precede, uma estrutura de linguagem e práticas de produção e de reprodução ancoradas ou amparadas por hábitos milenares*. Quando, segundo esse autor, há uma adaptação dessas novas técnicas (práticas) às anteriores, quer dizer, quando as novas práticas trazem com elas resíduos operacionais das antigas, há maior receptividade em relação às informações enunciadas. Ora, esse raciocínio sugere a existência de um lugar de passagem, um lugar "entre" o que já é assimilado ou conhecido e o que está sendo construído ou o desconhecido, fenômeno que se reproduz desde o início da humanidade. É nesse espaço "entre" que se situa a reflexão sobre o impresso e o eletrônico, não havendo, desse ponto de vista, por que polarizar conceitos decorrentes da cultura do papel e aqueles surgidos com as
"Villaça, Nízia. Impresso ou eletrônico? Um trajeto de leitura. Rio de Janeiro: Mauad, 2002: 13) 
(Lemos, André. "Cibercultu ra: alguns pontos para com preender a nossa época". Em: Lemos, André e Cunha, Paulo (orgs.) Olhares sobre a cibercultura. Porto Alegre: Sulina, 2003 12.23) novas tecnologias - esse procedimento cria um espaço vazio entre as duas formas culturais e dá origem, segundo a autora, a tecnofilias e tecnofobias.

Na dialética entre o "velho" e o "novo", há necessariamente um movimento inter-relacional. O "velho" traz em si elementos do novo, assim como o "novo" traz elementos do velho; esta, aliás, é uma condição sine qua non da existência do novo. Para haver assimilação de uma nova linguagem, é preciso que ela se apóie na "velha". Trata-se de uma condição para que a passagem de um momento para outro se dê. Assim, em vez de nos preocuparmos com o possível desaparecimento do livro impresso, deveríamos criar novas metodologias para situar e analisar um novo fenômeno e suas formas constitutivas.

O hipertexto, na condição de elemento construtivo desse novo, revela-se, assim, um novo paradigma para os estudos literários. Pensar essa problemática é relacionar métodos "velhos" com novos aspectos, e métodos novos com ancoragens teóricas no "velho". Uma de nossas hipóteses é que, na sociedade contemporânea pós-moderna, a existência de aspectos arcaicos convivendo com tecnologias avançadas é tanto uma condição quanto uma dada situação histórica: condição de existência desse fator pós-moderno e aspecto com que temos de lidar, traduzido por uma interface relacional, comunicacional, de origem teórico-reflexiva. No contexto em que as discussões atuais transitam, há tendências, já citadas, que variam de uma tecnofilia a uma tecnofobia, algo que, para André Lemos, constitui um falso problema*. Em seu modo de pensar, essa problemática não se resume a separar, de um lado, os otimistas e, do outro, os pessimistas. O que está em jogo é uma construção que busca evitar uma visão de futuro utópica ou distópica, e concentra suas forças na elaboração de uma fenomenologia social, quer dizer, na compreensão das diversas potencialidades e negatividades das tecnologias contemporâneas.

Umberto Eco, em palestra na biblioteca de Alexandria, considera que há três tipos de memória. A primeira é a orgânica, feita de carne e sangue, e administrada por nosso cérebro. A segunda, a mineral, tendo a humanidade, segundo o autor, conhecido dois tipos de memória mineral: a memória representada por tijolos de argila e obeliscos, e a memória eletrônica dos computadores que têm como base o silício. E a terceira, a memória vegetal, representada pelos papiros. Eco compara, 
desse modo, a morte das bibliotecas (memória do livro) a uma possível morte do livro, como ocorrido com os papiros e os obeliscos, afirmando, mesmo assim, sua crença em um futuro possível para os livros impressos, não museólogico, e sim como parte integrante da vida cotidiana e não das histórias passadas de cunho antropológico*.

É claro que as questões propostas por McLuhan em $\mathrm{Aga-}$ láxia de Gutenberg* foram pertinentes, embora não se tenham confirmado: a substituição da maneira linear de pensar, criada pela invenção da imprensa, por formas mais completas de percepção instauradas pela TV e por outros aparelhos eletrônicos. Ocorreu, sim, a continuidade da galáxia de Gutenberg em conjunto com estruturas informacionais criadas pelas novas tecnologias. Hoje, é a vez dos produtos da cibercultura se tornarem os vilões. Vale lembrar o gesto (já emblemático) de dom Cláudio Frollo olhando para a catedral Notre Dame de Paris, apoiado em um livro, e dizendo a seu visitante: "Isto matará aquilo” (Ceci tuera cela). A invenção da imprensa não matou a galáxia teológica e, para nós, o hipertexto (galáxia digital) não matará o livro.

Não se pode negar, porém, que há enormes diferenças entre a primeira galáxia de Gutenberg, a de McLuhan, e a atual. Só em relação ao computador, pode-se citar uma diferença fundamental: no início, eles eram lineares; hoje, deixaram de sê-lo, embora o interior das máquinas continue a funcionar de modo linear, de acordo com uma lógica binária de zero e um.

Como Eco mostra, o produto atual dos computadores "é uma explosão de fogos de artifícios semióticos. Seu modelo é menos uma linha reta do que uma verdadeira galáxia, onde todos podem captar nexos inesperados entre estrelas diferentes para formar uma nova imagem celestial em qualquer novo ponto de navegação"*.

Para finalizar, devemos considerar as diferentes especificidades e particularidades das produções textuais originárias do universo digital: o e-book e o CD-Rom, que comportam múltiplas possibilidades de navegações interativas, mas que, dadas as alternativas matematicamente limitadas, reduzem as associações infinitas que, por exemplo, o leitor tradicional tem diante de um tex to impresso, e finalmente o hipertexto, o qual, construído como fluxo contínuo, rompe com a linearidade da escrita tradicional.

\footnotetext{
"Eco, Umberto. "O livro contra-ataca", Folha de $S$. Paulo, Caderno "Mais", 14 de dezembro de 2003: 7)

" (McLuhan, Marshall. A galáxia de Gutenberg. São Paulo: Companhia Editora Nacional, 1977)
} "(Eco, Umberto. "O livro
contra-ataca". Ob. cit.: 7) 
"(Serres, Michel. "La dis tribution". Em: Hermès l: la communication. Paris: Minuit, 1969: 250)
Parece legítimo afirmar que, na pós-modernidade, ocorre a convivência - como afirmamos - de produtos oriundos da mais alta tecnologia com elementos tradicionais de um fazer livresco. O destino do livro impresso criado com base em signos apoiados no abecedário lhe confere uma quantidade infinita de associações, o que não ocorre com o CD-Rom. Não podemos negar, todavia, a ocorrência de uma nova literatura produzida em um ambiente digital como uma das novas formas adquiridas pela textualidade no fim do século XX e início do século XXI, e que, nesse sentido, deve ser incorporada aos estudos teóricos da literatura contemporânea.

Acreditamos que esse estudo se ofereça como uma reflexão apoiada na análise da criação textual e na observação das modalizações das comunidades virtuais particulares, algo que lhe conferirá semelhança aos estudos culturais: de um lado, preservar a especificidade do texto; de outro, destacar o contexto digital em que ele foi produzido. Essa nova textualidade se constrói em rede, deixando aberta a noção de autoria, embora as publicações, em razão dos direitos autorais e intelectuais, ainda se definam por autores tomados um a um. À semelhança das catedrais góticas, construídas por gerações inteiras, o hipertexto se revela como uma construção coletiva, pois é construído por milhares de vozes, desautorizando ou deslocando o conceito de autoria. Esse grupo composto de subjetividades, no entanto, não se limita a um conjunto de pessoas empenhadas em concluir um texto, pois é edificado sob a forma de acréscimos de novas intervenções subjetivas em permanente elaboração.

A ordem é uma ilha rara. Um arquipélago. A desordem é o oceano comum de onde essas ilhas emergem. A ressaca provoca a erosão das costeiras, e o solo, gasto, perde aos poucos sua ordem e se afunda. Em outra parte, um novo arquipélago surgirá das águas. A desordem está no fim dos sistemas e em seu começo. Tudo sempre vai na direção do caos e tudo vem dele, às vezes*. 
Luiz Antonio Garcia Diniz

Doutor em Letras pela Universidade Estadual Paulista Júlio de Mesquita Filho, UNESP, São Paulo. Sua tese tem por título "Cibercultura, hipertexto e cibercidade: a literatura e as artes no contexto das tecnologias digitais".

\section{Resumo}

Análise das implicações provocadas pelas novas tecnologias nas formas perceptivas (leitor) e nas técnicas de produção de textos (autor). A cibercultura, resultante da banalização dos computadores pessoais e das novas relações criadas pelas comunidades virtuais em um ambiente marcado pela interatividade, vem se impor como um novo paradigma, cujo foco são as relações estabelecidas entre a literatura, a cibercultura e a cibercidade com as novas formas textuais emergentes. Qual o papel do livro no ciberespaço e em ambientes imersivos? Como a temporalidade se define no texto contemporâneo, caracterizado por uma fractalidade crescente? Se o hipertexto se caracteriza como algo que se opõe ao texto linear, como se pode defini-lo em relação ao texto impresso, produto que se caracteriza pela noção de autor e de individualidade?

\begin{abstract}
The object of this study is to analyse the implications of the new technologies in the perceivable (reader) and technical (author) forms of textual production. Cyberculture, the result of the trivialisation of personal computers and of the new relationships created by virtual communities in an environment characterised by interactivity, has imposed a new paradigm. Our focus is the relationships established between literature, cyberculture and the cybercity by the newly emerging textual forms. What is the role of the book in cyberspace and in immersive environments? How would temporality be defined in the contemporary text, characterized by a growing fractality?
\end{abstract}

\section{Résumé}

L'analyse des implications provoquées par les nouvelles technologies dans les formes perceptives (lecteur) et techniques de production de textes (auteur) c'est le but de l'article. La cyberculture résultante des banalisations des ordinateurs personnels (PCs) et des nouvelles relations créées par les communautés virtuelles s'impose comme un nouveau paradigme. Notre regard privilégiera, donc, les relations établies entre la littérature, la cyberculture et la cybercité avec les nouvelles formes textuelles émergentes. Quel est le rôle du livre dans le cyberespace et dans les environnements immersifs? Comment pourraiton définir la temporalité dans le texte contemporain, caractérisé par une fractalité croissante? Si

\begin{abstract}
Palavras-chave
hipertexto, cibercultura, autoria, cibercidade, tex. tualidade.

Keywords hypertext, cyber culture, authorship, cyber city, textuality

Mots-clé

hypertexte, cyberculture, qualité d'auteur, cybercité,
\end{abstract} textualité. 
If hypertext is characterised as something opposed to linear text, how may we define hypertext in relation to printed text, a product characterised by the notion of the author and individuality? l’hypertexte se révèle comme quelque chose qui s'oppose au texte linéaire, comment pourraiton définir l'hypertexte par rapport au texte imprimé, produit caractérisé par la notion d'auteur et d'individualité? 